\title{
Recurrent asthma induced by toluene diisocyanate
}

\author{
DANIEL E BANKS, ROY J RANDO \\ From the Pulmonary Diseases Section, Department of Medicine, Tulane University School of Medicine, New \\ Orleans, Louisiana, USA
}

ABSTRACT A worker developed toluene diisocyanate induced asthma in 1974. On reassessment, 11 years after leaving the chemical plant where toluene diisocyanate was produced, he had no respiratory symptoms and normal bronchial reactivity in response to methacholine, and showed no reaction when challenged with a subirritant concentration of toluene diisocyanate. He developed asthma within five months of returning to the workplace. Repeat challenge testing showed bronchial hyperreactivity to methacholine and to the specific sensitising agent, toluene diisocyanate. This clinical pattern could be due to underlying toluene diisocyanate sensitivity with resolution and reappearance of hyperresponsiveness to methacholine and toluene diisocyanate reactivity associated with workplace toluene diisocyanate exposure. Alternatively, this worker may have developed sensitisation to toluene diisocyanate anew.

The natural history of occupational asthma, and of asthma induced by toluene diisocyanate in particular, is not predictable. Recent evidence indicates that some workers with isocyanate induced asthma have persistent symptoms long after leaving the workplace. ${ }^{1-3}$ Workers who have had isocyanate induced asthma, and whose chest symptoms and bronchial reactivity have resolved after they have left the workplace, have been described as being no longer sensitised to isocyanate. ${ }^{34}$ We report a worker who developed recurrent toluene diisocyanate induced asthma after having no isocyanate exposure for 11 years.

\section{Case report}

In 1974 the subject was 27 years old and employed as a maintenance worker in a chemical plant, where toluene diisocyanate was one of the chemicals produced. Three months after starting work a valve malfunctioned and he was drenched with isocyanate. The next morning he had chest tightness, wheeze, and sputum production. He received oral and inhaled bronchodilator treatment, and continued to

Address for reprint requests: Dr Daniel E Banks, Section of Pulmonary and Critical Care Medicine, West Virginia University School of Medicine, Morgantown, West Virginia 26506, USA.

Accepted 25 January 1988 work. After three months and many episodes of asthma in the workplace he was transferred to an area of minimal isocyanate exposure, but his symptoms persisted. Six months after the isocyanate spill he underwent challenge testing in our laboratory as described. ${ }^{5}$ Baseline spirometry was normal. Exposure to 5 parts per billion (ppb) (one quarter of the permissible exposure limit) of toluene diisocyanate for fifteen minutes resulted in a large immediate decline in the forced expiratory volume in one second $\left(\mathrm{FEV}_{1}\right)$, with wheeze and cough (fig 1). He was then transferred to a workplace where he was not exposed to chemicals.

His asthma symptoms gradually diminished, and after five years with no exposure to toluene diisocyanate he was able to discontinue inhaled and oral bronchodilators. In December 1985 the company closed the chemical free workplace, and he was referred for repeat testing with toluene diisocyanate. Baseline spirometric values were again normal and there was

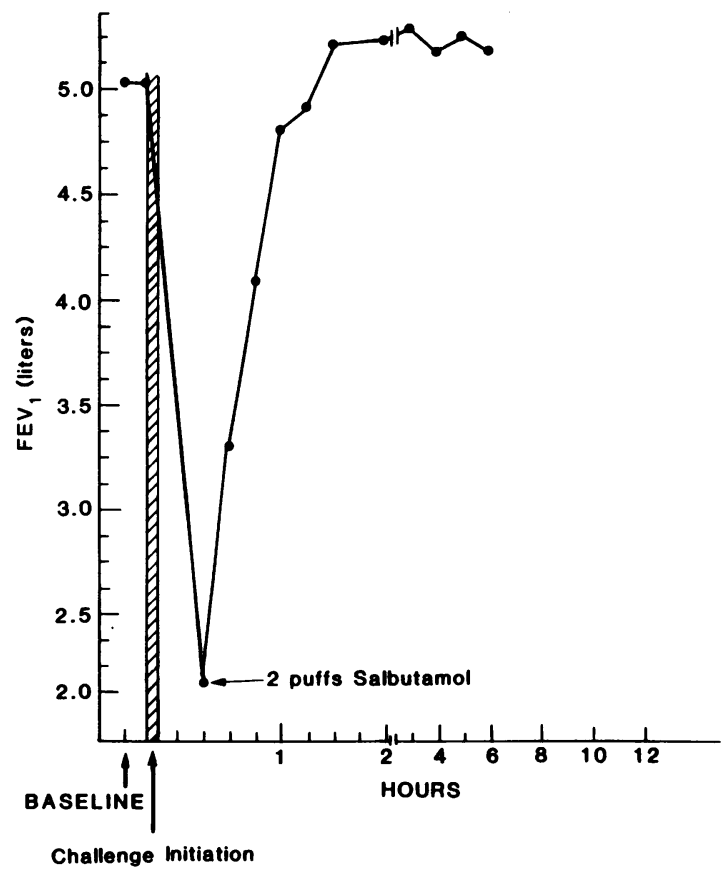

Fig 1 Exposure to 5 ppb of 80:20-2,4:2,6-toluene diisocyanate for 15 minutes in July 1974. There was an immediate fall in FEV, associated with symptoms of asthma. 


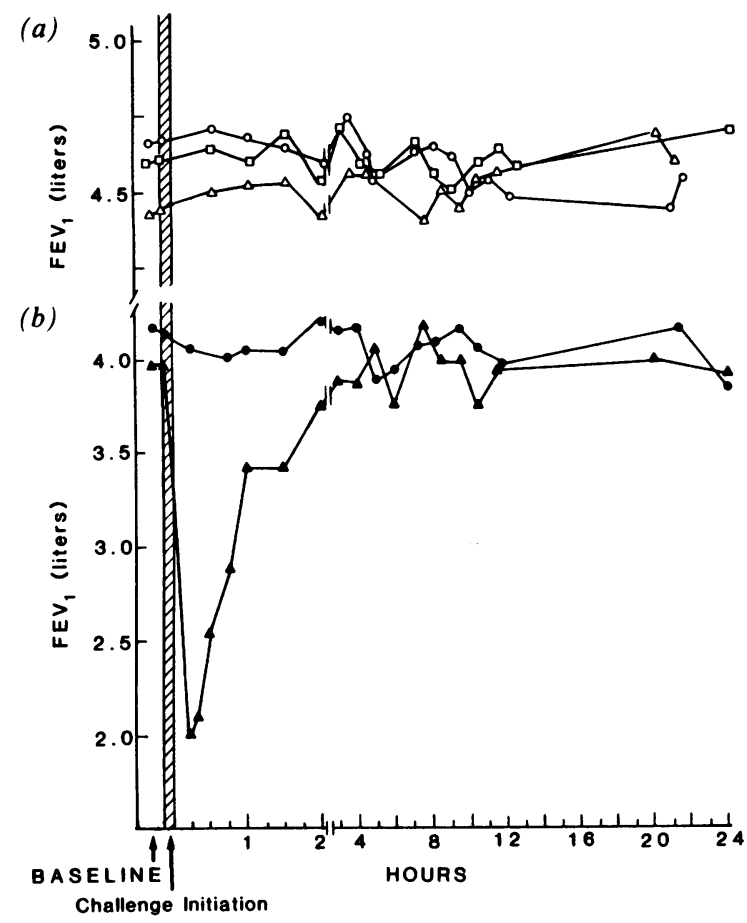

Fig 2 (a) FEV, after toluene diisocyanate challenge in December 1985, plotted on the top three lines. Day 1 ( $\square-\square)$ : " mock" exposure of 30 minutes; day 2 ( $\bigcirc-\bigcirc$ ): four hour exposure to 20.5 ppb 80:20-2,4:2,6toluene diisocyanate; day $3(\triangle-\triangle)$ : four hour exposure to $20.5 \mathrm{ppb}$. (b) Change in FEV after toluene diisocyanate challenge in May 1987, plotted on the two bottom lines. Day 1 (- ): "mock" exposure of 30 minutes; day 2 $(\Delta-\Delta): 15$ minute exposure to 8.8 ppb 80:20-2,4:2,6toluene diisocyanate.

no fall in $\mathrm{FEV}_{1}$ after inhalation of 640 cumulative units of methacholine. ${ }^{6}$ Isocyanate sensitivity was tested as described elsewhere. ${ }^{7}$ The worker was exposed to a "mock" challenge with toluene diisocyanate on day 1 (he was placed in the exposure chamber but no isocyanate exposure was provided). Because of the absence of bronchial hyperresponsiveness to methacholine we provided toluene diisocyanate exposures approximating to the permissible exposure level. After an exposure of $20.5 \mathrm{ppb}$ isocyanate for four hours on day 2 and $20 \cdot 2 \mathrm{ppb}$ for four hours on day 3 he developed no respiratory symptoms, and there was no fall in $\mathrm{FEV}_{1}$ (fig 2). We concluded that the worker had recovered from isocyanate induced asthma.

In January 1986 he returned to the chemical complex. He was well until April 1986, when he developed cough, sputum production, and chest tightness, beginning in the early evening, resolving spontaneously, and recurring early the following morning. These complaints worsened on days when toluene diisocyanate fumes were noticeable. In time these symptoms occurred during the work day. He stopped working in April 1987 and has not had further asthma or required additional bronchodilator treatment. When we reevaluated him in May 1987 he again had normal lung function, but now had bronchial hyperresponsiveness to methacholine (the dose of methacholine causing a $20 \%$ decline in $\mathrm{FEV}_{1}$ from baseline $\left(\mathrm{PD}_{20} \mathrm{FEV}_{1}\right)$ was 175 cumulative). Because of the increased responsiveness to methacholine, we planned a toluene diisocyanate exposure of about half the permissible exposure limit. Soon after beginning a 15 minute exposure to $8.8 \mathrm{ppb}$ isocyanate he developed nasal congestion, chest tightness, wheeze, dyspnoea, cough, and sputum production. After 15 minutes his FEV, had fallen to $51 \%$ of baseline (fig 2).

\section{Discussion}

The clinical presentation of recurrent isocyanate asthma probably represents a pattern of underlying sensitisation to toluene diisocyanate with resolution and reappearance of bronchial hyperresponsiveness. The results of challenge tests in December 1985 showed no methacholine or isocyanate hyperresponsiveness. Repeat toluene diisocyanate exposures after his return to the workplace provoked the return of methacholine hyperresponsiveness and isocyanate reactivity. The reappearance of isocyanate reactivity implies underlying isocyanate sensitisation. In a worker with isocyanate induced asthma isocyanate sensitisation could be lifelong and, like extrinsic asthma, remit after cessation of exposure, but recur when the allergen is reintroduced into the environment. Avoiding isocyanate exposure for some years can result in a negative response to an isocyanate inhalation challenge test, and lead investigators to conclude falsely that sensitivity to isocyanate has resolved. A similar case showing waxing and waning of bronchial hyperresponsiveness has been reported in the setting of occupationally induced asthma among snow crab processing workers. ${ }^{8}$

It is also possible that the worker's repeat exposures to toluene diisocyanate at the workplace caused sensitisation to occur anew. His comment that his respiratory symptoms were worse on days when isocyanate fumes were noticeable implies occasional high exposures. Such exposures are well recognised as increasing the risk of developing isocyanate induced asthma. ${ }^{9}$

With time a worker with toluene diisocyanate induced asthma may become symptom free and no longer have bronchial hyperresponsiveness to methacholine or isocyanate, yet again develop symptoms if workplace exposure is sufficient. In this case the most prudent course, even after proving that the worker no longer developed asthma in a controlled laboratory exposure, would have been avoidance of further isocyanate exposure.

\section{References}

1 Lozewicz S, Assoufi BK, Hawkins R, et al. Outcome of asthma induced by isocyanates. Br J Dis Chest 1987;81:14-22.

2 Paggiaro PL, Loi AM, Rossi O, et al. Follow-up study of patients with respiratory disease due to toluene diisocyanate (TDI). Clin Allergy 1984;14:463-9.

3 Moller DR, McKay RT, Bernstein IL, et al. Long-term follow-up of workers with TDI asthma [abstract]. Am Rev Respir Dis 1984;129(suppl):A159.

4 Butcher BT, O'Neil CE, Reed MA, et al. Development and loss of toluene diisocyanate reactivity: immunologic, pharmacologic, and provocative challenge studies. J Allergy Clin Immunol 1982;70:231-5. 
5 Butcher BT, Karr RM, O'Neil CE, et al. Inhalation challenge and pharmacologic studies of toluene diisocyanate (TDI)-sensitive workers. J Allergy Clin Immunol 1979;64:146-52.

6 Hendrick DJ, Fabbri LM, Hughes JM, et al. Modification of the methacholine inhalation test and its epidemiologic use in polyurethane workers. Am Rev Respir Dis 1986;133:600-4.

7 Banks DE, Barkman HW Jr., Butcher BT, et al. Absence of bronchial hyperresponsiveness to methacholine in a worker with methylene diphenyl diisocyanate (MDI)-induced asthma Chest 1986;89:389-93.

8 Cartier A, Malo J-L, Forest F, et al. Occupational asthma in snow crab-processing workers. J Allergy Clin Immunol 1984;74: 261-9.

9 Brooks SM. The evaluation of occupational airways disease in the laboratory and workplace. J Allergy Clin Immunol 1982;70: 56-66.

\section{Book notices}

Not Always on the Level. EJ Moran Campbell. (Pp 246; $£ 14.95$, £13.95 BMA members.) London: Memoir Club (British Medical Journal), 1988.

I worked for Moran Campbell at Hammersmith and with others fell under his spell. He was one of the leaders of the new wave of clinical scientists in Britain in the late 1950s and Clinical Physiology, which he wrote with Dickinson and Slater, was our bible. Extremely sharp, seeing every side of a problem, Moran was a marvellous discussant. Intensely loyal and kind to members of his circle (which extended far beyond respiratory physiologists), he presented an abrasive and aggressive front in argument with outsiders; at the time (in the 1960s) this was considered "la mode Hammersmith" but EJMC was an extreme example of the species. His early achievements were pioneering - the first comprehensive account (based on electromyography) of the actions of the respiratory muscles; examination of the sensation of breathlessness, leading to the length-tension inappropriateness theory; the first advocacy of controlled oxygen for hypercapnic respiratory failure. References to this work and these times form some of the most interesting vignettes in this book. Not Always on the Level is described as a collection of memoirs. Its 35 chapters (or scenes) are too disordered chronologically and too much has been omitted since 1969 for this to be called an autobiography. Several chapters have already been published in the British Medical Journal (1979). It has been poorly subedited: among the mistakes, Sir John McMichael appears as Sir John McMasters. The first half of the book is a straightforward account, in Moran's terse and direct style, of his parents, his early life, his medical student days (digs in Shepherds Bush), and his introduction to research. There is a sympathetic account of one of his mentors (Professor Samson Wright), who convinced a reluctant and impatient Moran (anxious to stride the clinical stage) that physiological principles were essential for understanding disease. The physiology course at the Middlesex Hospital (1943), first practical class: "We were split up into groups of four and given two projects: (1) How big is a medical student? and (2) How big is a potato? Four sacks of potatoes each weighing a stone were provided." Sammy loved Moran and inscribed his pupil's first book: "My son, more than the calf wishes to suck does the cow yearn to suckle." I imagine that his second mentor, RL Riley (Johns Hopkins, Baltimore), felt the same. There is a fascinating account (pp 90-1) of how Moran started to work on the respiratory muscles. "My little project arose out of watching the physiotherapists at work on the wards. They would try to train certain patients to improve the movement of one side of the chest." Moran never doubted the importance of simple clinical observations, and pursued their explanation relentlessly in the face of accepted dogma. Not surprisingly, he was also a compassionate and skilled physician, though the accounts of his clinical experiences in this book are melodramatic. As everyone knows, disaster struck when Moran moved to McMaster University in 1968 to become chairman of medicine of the newly founded medical school. His behaviour, always erratic, became bizarre ( $>$ 3SD from normal) and eventually manic-depressive psychosis was diagnosed. Although he made no further major scientific contributions (by his standards), he ran the department of medicine at McMaster for at least 10 years while this disease slowly increased its grip. The last third of the book deals with this period. It is an incoherent account of isolated events of psychotic (manic) behaviour, which (unaccompanied by any commentary from relatives, colleagues, or psychiatrists) is too egotistical and lacking in insight to be illuminating. In my opinion, much of this would have been better left unsaid. This section is redeemed by the last chapter, "On being manic depressive," which is a cogent account of what it is like to switch mood from excessively high to low. These memoirs will both interest and sadden Moran's many friends.

Asthma-The Facts. 2nd ed. DJ Lane, A Storr. (Pp 188; $£ 4.95$, paperback.) Oxford: Oxford University Press, 1987. ISBN 0-19-261692-7.

The second edition of this book, aimed at patients with asthma, individuals who have contact with asthma, and those who are just plain interested, has arrived eight years after the $D$ first edition. In that time the main changes in asthma treatment have been the earlier use of prophylaxis, higher $\mathrm{N}$ doses of inhaled steroids, and new drug delivery systems. At $\sigma$ the same time there has been an increasing emphasis on $N$ education of patient, parent, spouse, GP and non-respiratory $N$ and respiratory physicians alike, to increase compliance and $\sigma$ understanding and thereby achieve better control of asthma. Against a background of an apparent rise in the prevalence of asthma the new edition of this book, appropriately updated, $\mathbb{D}$ is to be warmly welcomed. Difficult concepts are easily explained and potentially contentious areas (such as hyposensitisation) are discussed clearly and rationally. At

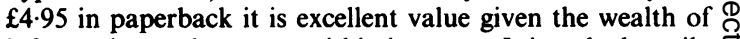
information and answers within its pages. It is to be heartily $\mathbb{D}$ recommended to all patients and those concerned in whatever way (for example, as parent or school teacher) in the care of asthma. 